\title{
The new media era of traffic radio media convergence analysis
}

\author{
Xiaoqiang Yan ${ }^{1,}$, Songmei Yuan ${ }^{2, b^{*}}$ \\ ${ }^{1}$ Harbin Institute of Technology, 92 West Dazhi Street, Harbin 150001, China \\ ${ }^{2}$ Harbin Institute of Technology, 92 West Dazhi Street, Harbin 150001, China \\ amrq1210@126.com , byuansm518@sina.com
}

Keywords: Media convergence; Ttraffic broadcasting; Mobile media; Mobile phone

\begin{abstract}
Broadcasting is that with the advent of technology development and dissemination of information play an important role in modern society. However, early the progress of the society and the media forms of development, have been brilliant broadcast in the mass but broadcast today has lost its former glory, and advantage development has become a broadcast development in the future. As for broadcast traffic, its typical broadcast and audience in media convergence to the development, is bound to be from the technical, policy, and the audience and other aspects to seek their own development path.
\end{abstract}

\section{Introduction}

With the development in traffic radio and traffic information spreading to a fixed audience, the dissemination of information plays an important role. However, with the New media, new leaps and bounds have been to ensure that traditional media (of radio traffic) have more affected on the audience. In the fast the rate of media broadcasting has been decline in many way such in advertising revenue, if the problem in radio traffic could be reduce, through cross media and new media complement traditional broadcasting cooperation, effectively expand the radio communication channe[1].we would then combine the advantages and characteristic of media broadcasting into the New Media fusion.

\section{Feasibility Analysis of Fusion, A Traffic Broadcast Media}

The Development of the Technology. When traffic radio has just set up, its main duty is to ease urban traffic, traffic information is the fundamental broadcasting station[2].For the radio traffic, traffic and information are the most important in media broadcasting field[3].

In the traffic information system, traffic radio has a traffic information processing center, which an operator set the number of received form different channels to traffic information "at present domestic traffic flow to deal with the traffic information is still manual or semi automated, but has not yet reached to the full automation collection of information, which is broadcast on the road service information, this emphasis on timely and accurate of the software system and software technology system will have some special requirements such as traffic information transmission and processing for example " Beijing traffic radio is used in automatic broadcasting system based on the company, please specially for traffic volume development "to meet Beijing traffic radio system requirements of traffic collection, transmission, editingprocess and quality management. 
With advanced electronic information collection methods, such as the application of electronic coil, electronic eye and editing platform system will also be upgraded, to which makes the process of traffic information is more accurate and more abundant means. The editor, the original information collected will no longer limited to text, but a more intuitive dynamic presentation in front of the editor, to ensure road editing more accurate, faster and more comprehensive.

The Direct Implementation of the National Policy. In recent years, the relevant state departments of broadcasting and Telecommunications policies and regulations have been made some changes and adjustments, to introduce some new measures to ensure the effectiveness of broadcasting.

Digital reform: digital broadcast domestic propulsion began in early twenty-first Century, The so-called digital broadcasting, is following the traditional amplitude modulation, FM radio af ter the third generation radio[2]. However, after years of development, the promotion of digital broadcasting is not just as one wish. Although the population of China is large compared wit $\mathrm{h}$ the developed countries, there is still a gap between the consumption capacities, digital broad casting mode to charge subscription, there is a long way to go. With the advent of the Internet broadcast, people are more willing to choose this kind of "do not spend money, listen to $t$ he world," the radio broadcast mode.

Triple play: During the "Tenth Five" plan, the Chinese government pledged to "promote te lecommunications, television, and computer (i.e. the Internet) triple play"[3]. After the develo pment, countries in the "Eleventh Five-Year Plan" proposed for the triple play this is to "Str engthening broadband communication network, Internet, digital television and next generation information infrastructure proposals promote the triple play"[4]. "Planning" of triple play in a dvancing technology and infrastructure has made a clear requirement, it also embodies the st rong determination of the government is determined to break triple play.

Listening Audience Behavior Change. First, change the listening behavior crowd. In previous years, the main broadcast crowd showing low levels of literacy, low income levels, low consumption levels and high age's situation. Now with the economic development, improve the level of urbanization, these features are gradually changing, car users are rising, a greater attention to the needs of the audience traffic. Meanwhile, college students and white-collar workers have become loyal audience broadcast, broadcast audience structural transition to a cultural level, high income, high consumption levels and low levels of ages. Secondly, the popular public radio listening time also changed. In the past, the main audience of the time listening to the radio in the morning, noon, and after dinner free time, broadcasters can allow people spend their leisure time listening in, but now the radio audience habits have been changed again, as people continue to enrich themselves in other activities like nightlife, broadcasting listen rate has been watered down in the evening, now broadcasting into a "road broadcasting", has become a prime-time morning and evening peak.

Broadcast Their Own Development Dilemma. The perceived need, competition and political pressures as well as social and technological innovation is the motivation of the development of media[7].Moment in full swing in the new media and traditional media, new media continue to explore and find new breakthrough that could be integrated with almost every popular introduction of new media broadcasting will have disappeared. Despite the development of broadcasting but regardless of how active in the new media, it's just a short follow. Streaming website appeared and each broadcast have built the site; micro-blogging letter appears, but also directly implanted into the radio program which, indeed, made these broadcasts can attract users, and adapt to the user's 
listening behavior. Although there isn't a breakthrough it's still architecture to other platforms, "limit the development."

\section{The Broadcast Media Convergence Way Traffic Analysis}

Fused Radio Methods. Integration of radio and television broadcasting to open another door into communication channels, but to follow the propagation mode tele-text television, and television media in the competition is not strong. Tele-text has resulted in a few weaknesses: the sound production and broadcast Kyo broadcast media, in terms of the production of the video is not dominant, less experienced, professional is not enough, resulting in poor picture quality as sound and picture are not synchronized phenomenon. Also teletext screen material is not effective, resulting in a single screen, boring, lack beauty; it is difficult to give the audience a strong visual impact formation.

In today's world the access to news is fast, this mean that traffic radio user tele-text weakening influence and impact cross wide of the program, not attract good audiences. To sustained the audience's attention, to private owners and professional drivers of note force more than a scattered, accompanied by weakening the radio traffic characteristics.

Network Integration Mode. For the audience, whether it is its own radio station website, or micro-blog, blog, other social networks, and third-party network platform, it presents station network integration remains limited to the Internet, conduct regional audience is limited, only sit-demand computer to come, listen, participate in interactive, and its concomitant less than traditional FM radio. Conventional FM radio broadcasts needed to receive or FM reception on the phone, without regard to where the audience can listen to the radio. Therefore, FM radio with a companion, where there are restrictions on the geographical and listening time. Also webcasts have place restrictions concomitant has been limited, but the geographical and unlimited listening time. So whether you can combine the two, derived from a new way to listen to broadcast it? The answer is yes, that is the arrival of the era of the fifth media, mobile media.

The way mobile media convergence. In recent years, mobile phones have been broadcast for budding. Hu Zhengrong communication scholars point out that the future of media, including three key elements: the convenience and mobility Portable, Personal and Participatory, and mobile media just to meet these three characteristics [8]. The current mobile radio applications can be divided into several areas: 1. a radio APP official media; 2. the integration of domestic radio program with "Dragonfly FM" headed + from mining type programs; 3. with "LIZHI FM" as the representative... Since media phone radio broadcast audio enthusiasts spread; 4. "Himalaya Radio" as the representative of the audio program upload and download broadcast-type mobile phone. Whatever type of broadcasting, carriers are required to accept phone, communication tools for the network. Carrier is now not a problem, but as a network of such communication tools, or can not be broadcast on a large scale mobile terminal extension. Network operators will be charged at the user network process network communications, broadcasting and sound transmission requires a lot of network traffic, audience, broadcast, network operators are tripartite interests, this model into one of the biggest problem - - the cost is listening to the radio. Once, we need to spend hundreds of dollars to buy a 24-hour radio you can listen to the radio program, broadcast mode current mobile phone network has given people more choices, but also let people choose by the "cost" of the constraints, therefore, development of the network and reduce traffic generated when the user uses the key to the future development of the mobile phone network broadcasting. 
Broadcast traffic is concerned, already broadcast on the radio and not be limited to the car radio playing, but more and more, and a new mobile terminal closely tied up, to move on the road, the state of the mobile Internet.

\section{Summary}

The fusion strategy, the emphasis is the broadcast media in audio media forms, multiplemedia fo rmats in the integration of development and expansion.Currently[9], mobile broadcasting has be en deep and digging out of the social value and value of the spread of mobile media, whic $\mathrm{h}$ fully reflects the personal characteristics of the propagation[10]. Firstly, the popularity of mobile phones has in favor of the spread, at high rates. With the gradual development of $\mathrm{m}$ obile media properties, "to have one" can become "a media staff." Secondly, accept autonom y. Ready to listen, listen to your heart Chang became a possibility. Again, directed to send $\mathrm{i}$ nformation becomes inevitable. Phone traffic radio can have on the content can be directiona 1 guidance, and even become the exclusive audience of personal broadcast platform. Audienc e interaction is a major feature of the phone broadcasting, mobile people can become self-m edia, become the media there is an individual, and reached through the micro-channel interac tive, mobile micro-blogging and other interactive platforms and programs, to reach to interact with other listeners. Thus, in the course of transportation among broadcast media convergen ce, Traffic Radio mobile application will become an important part.

Development of transport broadcast steeled from weak to strong, and now the situation is more and more listeners, but we should be prepared, especially in the new media age, the face of increasingly large mobile phone users, cannot still stuck in traffic radio the traditional model, it should be brave enough to face the opportunities and challenges, and the path of reform and innovation of the road ---- media convergence, long way to go.

\section{References}

[1] Shen Qiwu, Zhu Junjie. Under the background of the development trend of [J]. broadcastm edia fusion, 2011,06:15-17.

[2] Qin Xiaotian, Xie advanced traffic radio [J]. and development of modern visual thinking pro cess, 2007,01:39-42.

[3] Yang Qian. Traffic information broadcast broadcast and arrangement of [J]. visual field, 2 012,03:100-102.

[4] Fang Hua. Radio: DAB digital audio broadcasting [J]. electronic production technology of new generation, 2002,09:44-45+43.

[5] Information on http://wenku.baidu.com/link?url=H82A7JFp26UIBpQSGfpVYoXFFxR4ZDU1 e23xYgFDqsmMMebxsiCcf_cqJQ7f8XO5b2oLH1yT3AErogN1Tfg-aWMmpkCs8dA6ZICFAGx $\mathrm{xmOu}$

[6] The bulletin of the Standing Committee of the National People's Congress of the people' s Republic of China National Economic and social development eleventh five year plan for the [J]. of the people's Republic of China, 2006,03:178-221.

[7] Ding Baiquan. Media convergence concept, motivation and advantages and disadvantages of [J]. social science of Nanjing, 2011,11:92-99. 
[8] Yang Yang. mobile phone users to listen to audio programs. The empirical research on $\mathrm{t}$ he Chinese broadcast [J]. 2013,06:59-62.

[9] Lv Shangbin. Triple play and broadcast media development strategy of [J]. China broadc asting, 2011,10:17-21.

[10] Information on http://baike.baidu.com/link?url=VyKmeG-iamTSDjJnxmF2sASk3fdeeBVYip 9SBkKtg78zajBnH2uSfa5wkgAvhoTSi7iTdsel26hyLQTJVXrrY_ 